\title{
Epidural steroid compared to placebo injection in sciatica: a systematic review and meta-analysis
}

\author{
E. J. A. Verheijen ${ }^{1,2}$ - C. A. Bonke ${ }^{1}$ - E. M. J. Amorij ${ }^{1}$ C. L. A. Vleggeert-Lankamp ${ }^{1,2}$
}

Received: 3 February 2021 / Accepted: 18 April 2021 / Published online: 11 May 2021

(c) The Author(s) 2021

\begin{abstract}
Purpose The purpose of this systematic review and meta-analysis was to determine whether epidural steroid injections (ESI) are superior to epidural or non-epidural placebo injections in sciatica patients.

Methods The PubMed, Embase, Cochrane Library, and Web of science databases were searched for trials comparing ESI to epidural or non-epidural placebo. Risk of bias was assessed using the Cochrane RoB 2 tool. The primary outcome measures were pooled using a random-effects model for 6-week, 3-month, and 6-month follow-up. Secondary outcomes were described qualitatively. Quality of evidence was graded using GRADE classification.

Results Seventeen out of 732 articles were included. ESI was superior compared to epidural placebo at 6 weeks $(-8.6$ $[-13.4 ;-3.9])$ and 3 months $(-5.2[-10.1 ;-0.2])$ for leg pain and at 6 weeks for functional status $(-4.1[-6.5 ;-1.6])$, though the minimally clinical important difference (MCID) was not met. There was no difference in ESI and placebo for back pain, except for non-epidural placebo at 3 months $(6.9[1.3 ; 12.5])$. Proportions of treatment success were not different. ESI reduced analgesic intake in some studies and complication rates are low.

Conclusion The literature indicates that ESI induces larger improvements in pain and disability on the short term compared to epidural placebo, though evidence is of low to moderate quality and MCID is not met. Strong conclusions for longer follow-up or for comparisons with non-epidural placebo cannot be drawn due to general low quality of evidence and limited number of studies. Epidural injections can be considered a safe therapy.
\end{abstract}

Keywords Epidural steroid injection $\cdot$ Lumbar disc herniation $\cdot$ Lumbar radiculopathy $\cdot$ Placebo

\section{Introduction}

Sciatica is a common spinal condition with high reported lifetime prevalence and is generally caused by a lumbosacral disc herniation (LDH) [1]. Patients usually present with unilateral leg pain with ensuing disabilities. Other associated clinical manifestations include back pain, motor-sensory deficits, and reflex abnormalities [2]. Despite the debilitating physical burden, sciatica has a favourable prognosis due to

Communicated by NETHERLANDS.

$\triangle$ E. J. A. Verheijen

e.j.a.verheijen@lumc.nl

1 Department of Neurosurgery, Leiden University Medical Center, Albinusdreef 2, 2300 RC Leiden, The Netherlands

2 Department of Neurosurgery, Spaarne Gasthuis Hospital, Haarlem/Hoofddorp, The Netherlands its self-limiting essence and hence, most patients are initially treated conservatively [3].

It is assumed that sciatica symptoms are triggered by a complex interaction of compression-related, inflammatory, and immunological mechanisms [4]. Physical impingement of a nerve root from LDH is not necessarily sufficient to induce pain, as a substantial group of patients presents with neural compromise on imaging in absence of clinical symptoms and vice versa [5-7]. Possibly, in addition to nerve root compression, immunological and inflammatory processes play a key role. Exposure to nucleus pulposus tissue is assumed to cause an auto-immune response leading to cytokine production and involvement of pro-inflammatory cells. Additionally, vertebral end plate devascularization may strengthen this response [8-12].

These inflammatory processes are the primary target of epidural steroid injection (ESI) treatment. Through an interlaminar (IL), transforaminal (TF) or caudal approach anti-inflammatory medication can be deposited in close 
proximity of the affected nerve root, which is presumed to inhibit production of inflammatory mediators and to downregulate the immunological response. Subsequently, inflammation is decreased resulting in pain reduction and functional improvement for the patient [8,13-15].

Although several studies have investigated the efficacy of ESI in comparison with placebo, they have generated inconsistent results precluding an unequivocal recommendation on ESI therapy. However, despite the lack of consensus on efficacy, this treatment has been firmly established as a minimally invasive method for pain management in sciatica with continuously increasing utilization rates [16-18]. Therefore, this review explores the validity of ESI treatment compared to epidural and non-epidural placebo in sciatica patients in current practice.

\section{Methods}

This systematic review and meta-analysis were conducted in accordance with the PRISMA guidelines.

\section{Search and selection}

The PubMed, Embase, Cochrane Library and Web of Science databases were searched on August 20, 2020, using an all-encompassing search strategy constructed by an expert librarian. The search strategy combined strings for randomized-controlled trials with sciatica patients, treatment with ESI compared to epidural or non-epidural placebo and appropriate outcome measures (ESM 1). Retrieved studies were selected first on title and abstract by three independent reviewers (EV, CB, EA). Consequently, selected studies and previously published systematic reviews were subjected to citation tracking and all obtained articles were reviewed in full text. In case of a discrepancy, consensus was reached through discussion or consultation of a fourth reviewer (CVL).

\section{Inclusion and exclusion criteria}

Articles were eligible if they described an RCT that compared injection of steroid into the epidural space with injection of placebo using the same technique or with non-epidural placebo. All three techniques (caudal, IL and TF) were accepted. Epidural placebo was defined either as an inert substance without pharmacological activity (e.g. saline) or as a short-living local anaesthetic (e.g. lidocaine) delivered to the epidural space. Non-epidural placebo was defined as an inert substance without pharmacological activity administered into soft tissue surrounding the lumbar spine (e.g. subcutaneous). Studies were eligible if they provided data on sciatica patients, unless they only reported specifically on patients with a stenosis, or if they provided data separately for a subgroup of sciatica patients without stenosis. Studies were included if treatment efficacy was assessed using a validated instrument for pain or disability in at least 20 patients for a minimum follow-up of 2 weeks. Studies that evaluated pain without specifying whether this was leg pain were eligible as well, since leg pain is usually worse than back pain in sciatica patients. For assessment of pain, the visual analogue scale (VAS) and numerical rating scale (NRS) and for disability, the Oswestry Disability Index (ODI) and Roland-Morris Disability Questionnaire (RMDQ) were considered appropriate instruments. Only reports in English, Dutch, German, French, or Spanish were accepted.

\section{Risk-of-bias assessment}

The three reviewers individually assessed the risk of bias of included articles using the Cochrane risk of bias tool (RoB 2) [19]. For the second domain, the effect of assignment to intervention was determined. In addition to the published article, trial registrations and protocols were used if available to assess risk-of-bias questions, or the corresponding author was contacted for clarification. Differences between answers to the questions were resolved during a consensus meeting.

\section{Data extraction and analysis}

Descriptive and quantitative data were retrieved from each study by two reviewers independently with the third reviewer verifying the final data extraction sheet. Information was collected regarding authors, publication date, patients, interventions, primary and secondary outcomes and results. Leg pain, back pain and disability were assessed as the primary patient outcomes. Pain medication use and complications were assessed as secondary outcomes. For continuous outcome data, means and standard deviations (SD) and mean differences (MD) with corresponding standard error (SE) and $95 \%$ confidence interval (CI) adjusted for baseline differences were collected. Alternatively, unadjusted MDs and SE were calculated preferring the use of change scores to final values [20]. If SD was missing, the value was imputed preferably using SD values from the same study or else from a comparable study. For dichotomous outcome data, absolute numbers, percentages, risk ratio (RR) or odds ratio (OR) with SE or $95 \%$ CI were obtained. In case outcome data were only presented graphically, numeric data was extracted from the figure. Continuous data were converted to a $0-100$ scale for comparability purposes. Treatment arms of the same type within a study were combined (e.g. three steroid groups were merged) and analysed as a single intervention group [20].

Meta-analysis using random-effects model in R ( $\mathrm{R}$ Foundation for Statistical Computing, Vienna, Austria) was performed for pooling of primary outcomes if patient groups 
were considered sufficiently clinically homogeneous. Results were pooled separately for each epidural technique and together combining all three approaches for three follow-up timeframes: 6 weeks, 3 months and 6 months. Sensitivity analyses were performed for the combined pooled estimate. Sensitivity analysis for heterogeneity $\left(I^{2}\right)$ was conducted when $I^{2}>25 \%$. Publication bias was assessed using funnel plots and Egger's test but only discussed if assessment included at least five studies [21]. Quality of evidence for pooled results was graded using the GRADE system [22]. Secondary outcomes were assessed qualitatively. Detailed study data and figures are available as Electronic Supplementary Material (ESM).

\section{Results}

\section{Article selection}

The search yielded a total of 413 unique references of which 57 articles were selected for full-text assessment. Ultimately, 17 reports [15, 23-38] were included for this review (Fig. 1). Thirteen articles focussed on epidural placebo [15, 24-27,
$29,32-38]$, two on non-epidural placebo [23, 30] and two included both placebo groups [28, 31]. A more elaborate overview of study characteristics is given in ESM 2.

\section{Risk-of-bias assessment}

Of the 17 trials, five were considered low risk of bias [23, $26,28,31,32]$, two raised some concerns [15, 30] and ten studies were scored as high-risk [24, 25, 27, 29, 33-38]. Initially, the five low-risk reports were categorized as raising some concerns only due to unavailability of a pre-specified statistical analysis plan. Since a statistical analysis plan was unavailable for all studies, these five trials were judged as low risk (ESM 3).

An overview of study data used for meta-analysis is given in ESM 4. Publication bias data is presented in ESM 10.

\section{Treatment effect on leg pain}

\section{Epidural steroid versus epidural placebo}

For 6-week and for 3-month follow-up, the pooled estimate favoured ESI to epidural placebo for reduction of leg
Fig. 1 Flowchart of the article search and selection process

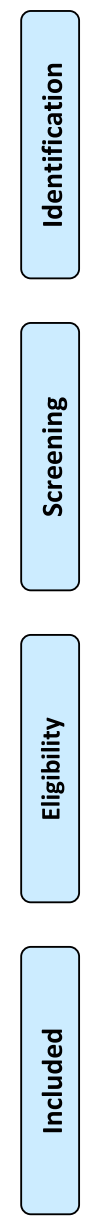

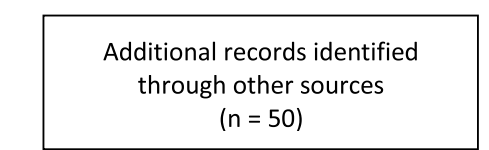

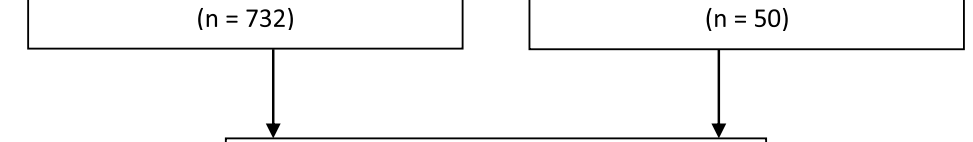

Records after duplicates removed $(n=413)$

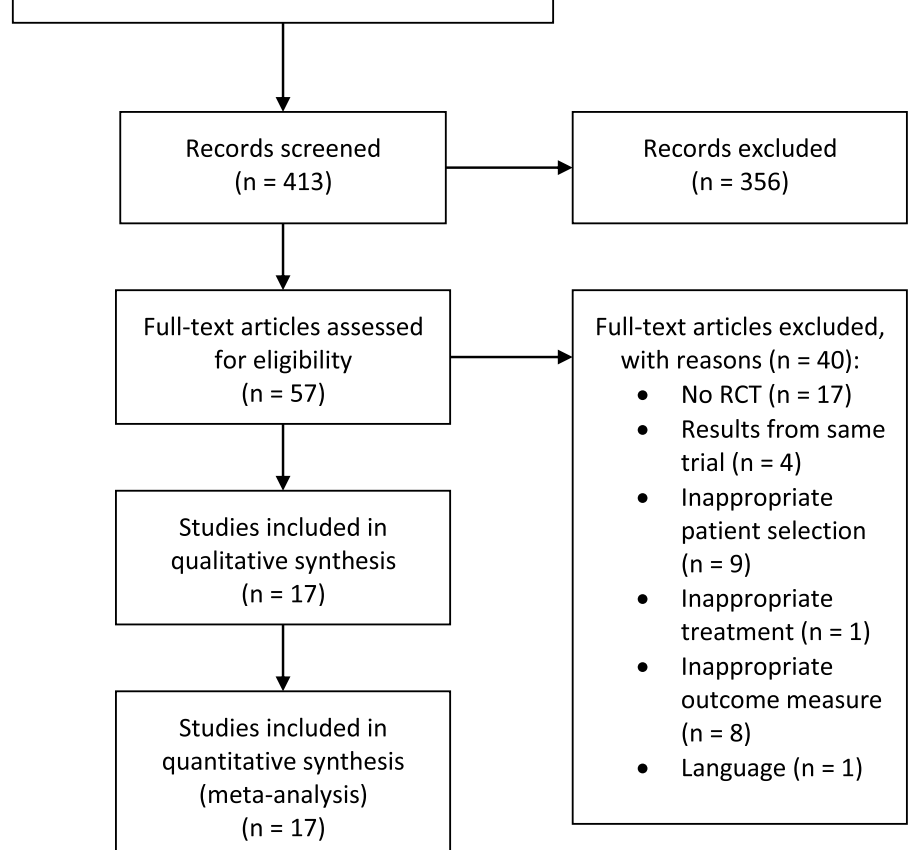


pain. Pooling for 6-month follow-up only demonstrated a statistically significant difference after exclusion of three studies [29, 32, 36] for heterogeneity (Table 1) (ESM 7). Assessment of publication bias was inconclusive for 3- and 6-month follow-up and showed an absence for 6-week follow-up. Sensitivity analyses demonstrated various changes in direction of the pooled estimate for all follow-up timeframes with the most pronounced shift being between sciatica patients with a radiological and patients with a clinical diagnosis for 6-week follow-up (ESM 11).

GRADE quality of evidence: low (ESM 12).

\section{Epidural steroid versus non-epidural placebo}

When comparing ESI to non-epidural placebo, the pooled estimate was nonsignificant for all three follow-up periods (Table 1) (ESM 7). Sensitivity analyses could only be performed for 6-week and 3-month follow-up and demonstrated large differences between effect estimates (ESM 11).

GRADE quality of evidence: low (6-week and 6-month) and moderate (3-month) (ESM 12).

\section{Treatment effect on back pain}

\section{Epidural steroid versus epidural placebo}

The pooled effect estimate was not significantly different between ESI and epidural placebo for all follow-up time frames (Table 2) (ESM 8). Sensitivity analyses affected the 6-week pooled result only slightly, whereas for 3-month follow-up larger variations were observed. For 6-month follow-up, sensitivity analysis showed favour for ESI when fluoroscopic image guidance was used and in patients with (sub) acute symptoms (ESM 11).
Table 2 Pooled effect estimates from continuous data for back pain

\begin{tabular}{lllll}
\multicolumn{2}{l}{ Primary analysis } & & \\
\hline $\begin{array}{l}\text { Number } \\
\text { of stud- }\end{array}$ & $\begin{array}{l}\text { Num- } \\
\text { ber of } \\
\text { patients }\end{array}$ & MD $(95 \%$ & $P$-value & $I^{2}(\%)$ \\
ies & & & \\
\hline
\end{tabular}

Epidural steroid versus epidural placebo

\begin{tabular}{|c|c|c|c|c|c|}
\hline 6-week FU & 3 & 290 & $\begin{array}{l}-2.9 \\
(-6.8 ; 0.9)\end{array}$ & 0.14 & 0 \\
\hline 3-month FU & 2 & 227 & $\begin{array}{c}0.7 \\
(-23.5 ; 25.0)\end{array}$ & 0.95 & 94 \\
\hline 6-month FU & 2 & 225 & $\begin{array}{l}-4.9 \\
(19.9 ; 10.2)\end{array}$ & 0.53 & 84 \\
\hline \multicolumn{6}{|c|}{ Epidural steroid versus non-epidural placebo } \\
\hline 6-week FU & 2 & 302 & $\begin{array}{l}-1.7 \\
(-6.6 ; 3.1)\end{array}$ & 0.49 & 34 \\
\hline 3-month FU & 2 & 298 & $\begin{array}{c}6.9 \\
(1.3 ; 12.5)\end{array}$ & 0.02 & 42 \\
\hline 6-month FU & 2 & 294 & $\begin{array}{c}1.3 \\
(-2.2 ; 4.9)\end{array}$ & 0.46 & 0 \\
\hline
\end{tabular}

A negative MD indicates a favour for ESI; a positive MD indicates a favour for placebo. Sensitivity analysis of heterogeneity was not feasible for all follow-up time frames due to the limited number of studies

$C I$ confidence interval, $F U$ follow-up, $M D$ mean difference

GRADE quality of evidence: moderate (6-week), very low (3-month) and low (6-month) (ESM 12).

\section{Epidural steroid versus non-epidural placebo}

The pooled effect estimate was only statistically significant for 3-month follow-up in favour of non-epidural placebo (Table 2) (ESM 8). Sensitivity analyses were not feasible due to the limited number of studies included.

GRADE quality of evidence: moderate (ESM 12).

Table 1 Pooled effect estimates from continuous data for leg pain and adjusted for sensitivity analysis of heterogeneity

\begin{tabular}{|c|c|c|c|c|c|c|c|c|c|c|}
\hline & \multicolumn{5}{|c|}{ Primary analysis } & \multicolumn{5}{|c|}{ Sensitivity analysis for heterogeneity } \\
\hline & $\begin{array}{l}\text { Number } \\
\text { of studies }\end{array}$ & $\begin{array}{l}\text { Num- } \\
\text { ber of } \\
\text { patients }\end{array}$ & MD $(95 \% \mathrm{CI})$ & $P$-value & $I^{2}(\%)$ & $\begin{array}{l}\text { Number } \\
\text { of studies }\end{array}$ & $\begin{array}{l}\text { Num- } \\
\text { ber of } \\
\text { patients }\end{array}$ & $\operatorname{MD}(95 \% \mathrm{CI})$ & $P$-value & $I^{2}(\%)$ \\
\hline \multicolumn{11}{|c|}{ Epidural steroid versus epidural placebo } \\
\hline 6-week FU & 10 & 997 & $-8.6(-13.4 ;-3.9)$ & $<0.01$ & 70 & 7 & 830 & $-5.9(-8.7 ;-3.2)$ & $<0.01$ & 14 \\
\hline 3-month FU & 10 & 1188 & $-5.2(-10.1 ;-0.2)$ & 0.04 & 83 & 7 & 792 & $-6.8(-10.3 ;-3.2)$ & $<0.01$ & 25 \\
\hline 6-month FU & 7 & 677 & $-2.7(-8.0 ; 2.6)$ & 0.31 & 75 & 4 & 330 & $-5.1(-8.0 ;-2.3)$ & $<0.01$ & 0 \\
\hline \multicolumn{11}{|c|}{ Epidural steroid versus non-epidural placebo } \\
\hline 6-week FU & 4 & 399 & $-8.1(-17.8 ; 1.6)$ & 0.10 & 80 & 2 & 302 & $-0.1(-3.9 ; 3.7)$ & 0.97 & 0 \\
\hline 3-month FU & 3 & 337 & $-1.0(-17.9 ; 15.8)$ & 0.90 & 92 & $*$ & - & - & - & - \\
\hline 6-month FU & 2 & 294 & $1.7(-2.1 ; 5.4)$ & 0.38 & 0 & $*$ & - & - & - & - \\
\hline
\end{tabular}

A negative MD indicates a favour for ESI; a positive MD indicates a favour for placebo

$C I$ confidence interval, $F U$ follow-up, $M D$ mean difference

*The limited number of studies did not allow for sensitivity analysis of heterogeneity 


\section{Treatment effect on functional status}

\section{Epidural steroid versus epidural placebo}

ESI was favoured to placebo for improvement of disability at 6-week follow-up, and at 3-month follow-up after adjustment for heterogenic studies [31]. For 6-month follow-up, none of the interventions was favoured (Table 3 ) (ESM 9). Assessment of publication bias was inconclusive. Sensitivity analyses resulted in different pooled estimates at 3 and 6-month follow-up (ESM 11).

GRADE quality of evidence: moderate (6-week), low (3-month) and very low (6-month) (ESM 12).

\section{Epidural steroid versus non-epidural placebo}

The effect estimate favoured none of the interventions for 6-week, 3- and 6-month follow-up (Table 3) (ESM 9).
Sensitivity analyses were not feasible due to the limited number of studies included.

GRADE quality of evidence: moderate (ESM 12).

\section{Proportions of treatment success}

For studies with treatment success defined as $\geq 50 \%$ improvement in pain scores, neither ESI nor epidural placebo were favoured at 6-week, 3-month and 6-month followup (Table 4) (ESM 7). Sensitivity analyses produced varying results with mostly minor differences in effect estimates (ESM 11).

GRADE quality of evidence: high (6-week) and very low (3-month and 6-month) (ESM 12).

Pooling of success data on disability ( $\geq 50 \%$ improvement in ODI scores) favoured none of the interventions for 3- and 6-month follow-up, while 6-week data was lacking

Table 3 Pooled effect estimates from continuous data for functional status and adjusted for sensitivity analysis of heterogeneity

\begin{tabular}{|c|c|c|c|c|c|c|c|c|c|c|}
\hline & \multicolumn{5}{|c|}{ Primary analysis } & \multicolumn{5}{|c|}{ Sensitivity analysis for heterogeneity } \\
\hline & $\begin{array}{l}\text { Number } \\
\text { of studies }\end{array}$ & $\begin{array}{l}\text { Number } \\
\text { of patients }\end{array}$ & $\mathrm{MD}(95 \% \mathrm{CI})$ & $P$-value & $I^{2}(\%)$ & $\begin{array}{l}\text { Number } \\
\text { of studies }\end{array}$ & $\begin{array}{l}\text { Number } \\
\text { of patients }\end{array}$ & MD $(95 \% \mathrm{CI})$ & $P$-value & $I^{2}(\%)$ \\
\hline \multicolumn{11}{|c|}{ Epidural steroid versus epidural placebo } \\
\hline 6-week FU & 6 & 624 & $-4.1(-6.5 ;-1.6)$ & $<0.01$ & 35 & 5 & 531 & $-2.5(-4.5 ;-0.5)$ & 0.01 & 0 \\
\hline 3-month FU & 9 & 981 & $-2.5(-5.5 ; 0.5)$ & 0.10 & 71 & 8 & 912 & $-4.1(-5.9 ;-2.3)$ & $<0.01$ & 0 \\
\hline 6-month FU & 6 & 653 & $-1.0(-5.4 ; 3.5)$ & 0.67 & 84 & 2 & 239 & $-2.6(-6.1 ; 0.8)$ & 0.14 & 0 \\
\hline \multicolumn{11}{|c|}{ Epidural steroid versus non-epidural placebo } \\
\hline 6-week FU & 2 & 302 & $-0.8(-3.3 ; 1.6)$ & 0.52 & 25 & $*$ & - & - & - & - \\
\hline 3-month FU & 2 & 298 & $4.0(-3.0 ; 11.0)$ & 0.26 & 83 & $*$ & - & - & - & - \\
\hline 6-month FU & 2 & 294 & $2.8(-3.9 ; 9.5)$ & 0.41 & 84 & $*$ & - & - & - & - \\
\hline
\end{tabular}

A negative MD indicates a favour for ESI; a positive MD indicates a favour for placebo

$C I$ confidence interval, $F U$ follow-up, $M D$ mean difference

*The limited number of studies did not allow for sensitivity analysis of heterogeneity

Table 4 Pooled effect estimates from proportional data for leg pain and functional status, and adjusted for sensitivity analysis of heterogeneity

\begin{tabular}{|c|c|c|c|c|c|c|c|c|}
\hline \multicolumn{4}{|c|}{ Primary analysis } & \multicolumn{5}{|c|}{ Sensitivity analysis for heterogeneity } \\
\hline $\begin{array}{l}\text { Number of } \\
\text { studies }\end{array}$ & $\begin{array}{l}\text { Number of } \\
\text { patients }\end{array}$ & $P$-value & $I^{2}(\%)$ & $\begin{array}{l}\text { Number of } \\
\text { studies }\end{array}$ & $\begin{array}{l}\text { Number of } \\
\text { patients }\end{array}$ & $\mathrm{RR}(95 \% \mathrm{CI})$ & $P$-value & $I^{2}(\%)$ \\
\hline
\end{tabular}

\begin{tabular}{|c|c|c|c|c|c|c|c|c|c|c|}
\hline \multicolumn{11}{|c|}{$\geq 50 \%$ improvement in pain scores } \\
\hline 6-week FU & 2 & 150 & $2.3(0.9 ; 5.9)$ & 0.08 & 81 & $*$ & - & - & - & - \\
\hline 3-month FU & 5 & 487 & $1.1(1.0 ; 1.3)$ & 0.15 & 51 & 4 & 418 & $1.1(1.0 ; 1.2)$ & 0.29 & 0 \\
\hline 6-month FU & 5 & 487 & $1.1(0.9 ;-1.3)$ & 0.24 & 60 & 2 & 178 & $1.0(0.7 ; 1.4)$ & 0.98 & 24 \\
\hline \multicolumn{11}{|c|}{$\geq 50 \%$ improvement in ODI scores } \\
\hline 3-month FU & 3 & 360 & $1.1(0.9 ; 1.2)$ & 0.43 & 28 & 2 & 240 & $1.1(1.0 ; 1.3)$ & 0.09 & 0 \\
\hline 6-month FU & 3 & 360 & $1.1(0.9 ; 1.4)$ & 0.50 & 72 & 2 & 240 & $1.0(0.8 ; 1.1)$ & 0.66 & 0 \\
\hline
\end{tabular}

$\mathrm{RR}>1$ indicates a favour for ESI; RR $<1$ indicates a favour for placebo

$C I$ confidence interval, $F U$ follow-up, $R R$ risk ratio

*The limited number of studies did not allow for sensitivity analysis of heterogeneity 
(Table 4) (ESM 9). Sensitivity analyses were not feasible due to similarity in methodology between trials.

GRADE quality of evidence: very low (ESM 12).

Success data from non-epidural placebo studies could not be pooled due to varying definitions of success. Data on proportions of treatment success are summarized in ESM 5.

\section{Treatment effect on pain medication use}

Acetaminophen use was significantly more reduced after ESI at 6 weeks, but not at 3 weeks [25]. Diclofenac usage was described in one study [27], but the results seemed unrealistic as an inordinate maximum daily intake of 26 tablets was recorded. (Non)opioid analgesic usage was not found to be different between treatments at one month [26], while stronger NSAID and morphine reductions were observed after ESI at 6 weeks [31]. Three other trials all demonstrated equal morphine equivalents during 2-year follow-up [34-36]. For analgesic usage after ESI and non-epidural placebo [23, 30], no significant differences between treatment groups were found for up to 1-year follow-up. These data are summarized in ESM 6.

\section{Adverse events}

Five articles [28, 30, 33, 34, 37] reported absence of any complication due to ESI or placebo during follow-up. Of the remaining 12 trials, one study [32] described a retroperitoneal hematoma after ESI. Several studies [25, 34-36] mentioned periprocedural complications without adverse consequences: dural punctures (1.5\% of procedures) [ 25 , $35]$, intravascular infiltrations $(4.1 \%)[29,36]$, nerve root irritations (1.5\%) [36] and vasovagal response after placebo $(0.8 \%)$ [29]. Several minor adverse events similarly occurred in both treatment arms: headache (14.2\%) [15, 23, 25, 27 , 38], local pain (15.6\%) [27, 31], tinnitus (5.5\%) [27] and nausea $(8.2 \%)[23,27]$. In the steroid group, single cases of weight gain [27], nonlocal rash [26], irregular periods for several months [24] and two patients with backache and hypotension [15] were reported. In the placebo group, temporary worsening of pain (10.0\%) [26] and one case of thoracic pain [38] were described.

\section{Discussion}

This review has demonstrated that ESI results in significantly greater leg pain relief and functional improvement compared to epidural placebo at 6 weeks in patients with sciatica. Caudal and TF injections provided more leg pain relief than IL injections and patients with radiologically confirmed lumbar disc herniation benefitted more than clinically diagnosed patients. In comparison with non-epidural placebo, ESI did not result in more improved leg pain at 6 weeks, although in patients explicitly diagnosed with disc herniation ESI had considerably more effect. For disability and back pain differences were smaller and non-significant.

At 3 months, ESI only resulted in better improvement of leg pain compared to epidural placebo. For other 3-month and all 6-month outcomes, ESI did not demonstrate greater efficacy regardless of the type of placebo. However, these results are to be expected since sciatica is considered a selflimiting condition with a favourable prognosis and steroids are presumed to have only a temporary effect of weeks to months that attenuates gradually. For epidural placebo, TF and IL steroid injections were generally more effective than the caudal approach while for non-epidural placebo differences between epidural routes were less distinct. Differences in treatment efficacy between ESI and placebo injections were mostly not statistically significant and overall, quality of evidence was moderate to very low.

Several authors consider control injections into the epidural space to be no true placebos, due to their assumed physiological and mechanical effects [39-42]. Instead, they assume that non-epidural injections with an inactive injectate into inactive tissues are genuine placebos. The effect estimate between ESI and non-epidural placebo therapy would expectedly be larger than between ESI and epidural placebo. Interestingly, pooled estimates between ESI and epidural placebo more often favoured steroids than comparisons between ESI and non-epidural placebo. However, due to the very limited number of non-epidural placebo studies it is possible that this result may be changed by conclusions from future trials.

Although several trials have compared ESI to (non-)epidural placebo for sciatica, the study populations and methods broadly differ. Varying aetiology, duration of symptoms, injection contents, placebo types and concomitant therapies introduce clinical heterogeneity which can lead to inaccurate effect estimates and reduced generalizability complicating appropriate conclusions for clinical practice [11, 43, 44]. In order to minimize clinical heterogeneity, all three epidural approaches and placebo types were assessed separately. Additionally, only studies that addressed sciatica patients with a clinical diagnosis or with radiologically confirmed LDH were accepted and assessed independently in sensitivity analyses among other variables. Furthermore, all effect estimates were calculated for three follow-up periods, which allowed for the use of multiple data from primary studies and minimized pooling of less compatible data (e.g. 1-month data used for 3-month effect). Hence, the results in our review are based on analyses of patient groups and treatments with maximized clinical homogeneity.

While ESI induces significantly greater improvement compared to epidural placebo at 6 weeks and 3 months, the absolute treatment differences appear to be modest. A 
minimally clinical important difference (MCID) for pain and disability has been proposed by a consensus group of experts of, respectively, 10 and 15 points, both on a $0-100$ scale [45]. Several of the included studies demonstrated results not meeting this MCID and consequently, the pooled effect estimates are lower than the proposed thresholds. However, the effect of ESI may be obscured by the use of continuous data since 'responders' and 'non-responders' exist [28, 46]. Hence, categorical data based on a pre-defined cut-off condition may be more suitable and is common practice in spinal intervention research, but authors often use variable definitions for 'success' and 'failure' strongly reducing comparability. Therefore, we only pooled studies with the same definition of 'success'. Simultaneously, omitting studies with other definitions may introduce bias. In this review, no significant differences in treatment success based on categorical data were observed. The use of a standardized definition in future trials would allow for pooling of more studies that could affect this result [45, 47-50]. Additionally, identification of subgroups of patients more responsive to ESI could justify steroid injections for these specific groups $[28,35,51]$. Although some sensitivity analyses identified more responsive subgroups (e.g. radiological versus clinical diagnosis for 6-week leg pain), these results must be interpreted with caution due to the limited number of studies included in each analysis.

In addition to treatment efficacy, complications must be considered when reviewing the validity of ESI therapy in clinical practice. Complications can generally be associated with needle placement or with administration of corticosteroids. In our review, only one patient with a serious complication and several minor events were described. This is in accordance with the observations from large cohort studies that the most frequently reported complications are minor and transient, but serious complications can develop, although very rarely and that, with correct safety measures, ESI can be considered a safe therapy [52-58].

Our review is limited by the paucity of literature on ESI for sciatica. A relatively small number of studies was eligible for inclusion particularly for comparisons with non-epidural placebo. Therefore, sensitivity analyses for each epidural approach separately were not feasible. Additionally, this paucity of literature complicated the interpretation of sensitivity analyses and publication bias [59]. Furthermore, the wide variety of definitions of treatment success precluded pooling of all available studies for categorical data.

The increasing demand for evidence-based medicine calls for studies with appropriate methodological quality and applicability [60-62]. Future studies that compare ESI to (non-)epidural placebos should consider the aetiology of sciatica and carefully monitor concomitant therapy. Moreover, studies should use a standardized cut-off condition for treatment success and focus on clinical, radiological and pathological features that can differentiate between responders and non-responders.

With the current evidence, ESI can be recommended as short-term pain management therapy compared to epidural placebo, although it must be stressed that generally MCID is not met. ESI has no proven additional value at 3 and 6 months or compared to non-epidural placebo at present. Absolute treatment differences are modest, but possibly subgroups of patients exist that will benefit more than others. With appropriate safety measures, ESI is a safe treatment. In clinical practice, physicians and patients should discuss the possible small short-term benefits and complications of ESI in a process of shared decision-making.

Supplementary Information The online version contains supplementary material available at https://doi.org/10.1007/s00586-021-06854-9.

Authors' contributions All authors contributed to the study conception and design. Material preparation, data collection and analysis were performed by EV, CB and EA. The first draft of the manuscript was written by EV, CB, EA and CVL and all authors commented on previous versions of the manuscript. All authors read and approved the final manuscript.

Funding No funding was sought or received.

Data availability All data generated or analysed during this study are included in this published article and its supplementary information files.

\section{Declarations}

Conflicts of interest The first author is sponsored by Achmea Health Insurance the Netherlands and Ynske Meyes fund.

Open Access This article is licensed under a Creative Commons Attribution 4.0 International License, which permits use, sharing, adaptation, distribution and reproduction in any medium or format, as long as you give appropriate credit to the original author(s) and the source, provide a link to the Creative Commons licence, and indicate if changes were made. The images or other third party material in this article are included in the article's Creative Commons licence, unless indicated otherwise in a credit line to the material. If material is not included in the article's Creative Commons licence and your intended use is not permitted by statutory regulation or exceeds the permitted use, you will need to obtain permission directly from the copyright holder. To view a copy of this licence, visit http://creativecommons.org/licenses/by/4.0/.

\section{References}

1. Konstantinou K, Dunn KM (2008) Sciatica: review of epidemiological studies and prevalence estimates. Spine (Phila Pa 1976) 33(22):2464-2472. https://doi.org/10.1097/BRS.0b013e3181 $83 \mathrm{a} 4 \mathrm{a} 2$

2. Koes BW, van Tulder MW, Peul WC (2007) Diagnosis and treatment of sciatica. BMJ 334(7607):1313-1317. https://doi.org/10. 1136/bmj.39223.428495.BE 
3. Deyo RA, Mirza SK (2016) Clinical practice: herniated lumbar intervertebral disk. N Engl J Med 374(18):1763-1772. https://doi. org/10.1056/NEJMcp 1512658

4. Stafford MA, Peng P, Hill DA (2007) Sciatica: a review of history, epidemiology, pathogenesis, and the role of epidural steroid injection in management. Br J Anaesth 99(4):461-473. https://doi.org/ 10.1093/bja/aem 238

5. Janardhana AP, Rajagopal RS, Kamath A (2010) Correlation between clinical features and magnetic resonance imaging findings in lumbar disc prolapse. Indian J Orthop 44(3):263-269. https://doi.org/10.4103/0019-5413.65148

6. van Rijn JC, Klemetso N, Reitsma JB, Majoie CB, Hulsmans FJ, Peul WC, Bossuyt PM, Heeten GJ, Stam J (2006) Symptomatic and asymptomatic abnormalities in patients with lumbosacral radicular syndrome: clinical examination compared with MRI. Clin Neurol Neurosurg 108(6):553-557. https://doi.org/10. 1016/j.clineuro.2005.10.003

7. el Barzouhi A, Vleggeert-Lankamp CL, Lycklama à Nijeholt GJ, Van Der Kallen BF, van den Hout WB, JacobsKoesPeul WCBWWC (2013) Magnetic resonance imaging in follow-up assessment of sciatica. N Engl J Med 368(11):999-1007. https:// doi.org/10.1056/NEJMoa1209250

8. McLain RF, Kapural L, Mekhail NA (2005) Epidural steroid therapy for back and leg pain: mechanisms of action and efficacy. Spine J 5(2):191-201. https://doi.org/10.1016/j.spinee. 2004.10.046

9. Mulleman D, Mammou S, Griffoul I, Watier H, Goupille P (2006) Pathophysiology of disk-related sciatica I.--evidence supporting a chemical component. Jt Bone Spine 73(2):151158. https://doi.org/10.1016/j.jbspin.2005.03.003

10. Wang K, Bao JP, Yang S, Hong X, Liu L, Xie XH, Wu XT (2016) A cohort study comparing the serum levels of pro- or anti-inflammatory cytokines in patients with lumbar radicular pain and healthy subjects. Eur Spine J 25(5):1428-1434. https:// doi.org/10.1007/s00586-015-4349-4

11. Valat JP, Genevay S, Marty M, Rozenberg S, Koes B (2010) Sciatica. Best Pract Res Clin Rheumatol 24(2):241-252. https:// doi.org/10.1016/j.berh.2009.11.005

12. Knezevic NN, Jovanovic F, Voronov D, Candido KD (2018) Do corticosteroids still have a place in the treatment of chronic pain? Front Pharmacol 9:1229. https://doi.org/10.3389/fphar. 2018.01229

13. Collighan N, Gupta S (2009) Epidural steroids. Contin Educ Anaesth Crit Care Pain 10(1):1-5. https://doi.org/10.1093/bjace accp/mkp043

14. Starkweather A, Witek-Janusek L, Mathews HL (2005) Neural-immune interactions: implications for pain management in patients with low-back pain and sciatica. Biol Res Nurs 6(3):196-206. https://doi.org/10.1177/1099800404272221

15. Nandi J, Chowdhery A (2017) A randomized controlled clinical trial to determine the effectiveness of caudal epidural steroid injection in lumbosacral sciatica. J Clin Diagn Res. https://doi. org/10.7860/jcdr/2017/21905.9392

16. Manchikanti L, Falco FJ, Singh V, Pampati V, Parr AT, Benyamin RM, Fellows B, Hirsch JA (2012) Utilization of interventional techniques in managing chronic pain in the Medicare population: analysis of growth patterns from 2000 to 2011. Pain Physician 15(6):E969-982

17. Friedly J, Chan L, Deyo R (2007) Increases in lumbosacral injections in the medicare population: 1994 to 2001. Spine (Phila Pa 1976) 32(16):1754-1760. https://doi.org/10.1097/ BRS.0b013e3180b9f96e

18. Manchikanti L, Pampati V, Falco FJ, Hirsch JA (2013) Assessment of the growth of epidural injections in the medicare population from 2000 to 2011. Pain Physician 16(4):E349-364
19. Sterne JAC, Savović J, Page MJ, Elbers RG, Blencowe NS, Boutron I, Cates CJ, Cheng H-Y, Corbett MS, Eldridge SM, Emberson JR, Hernán MA, Hopewell S, Hróbjartsson A, Junqueira DR, Jüni P, Kirkham JJ, Lasserson T, Li T, McAleenan A, Reeves BC, Shepperd S, Shrier I, Stewart LA, Tilling K, White IR, Whiting PF, Higgins JPT (2019) RoB 2: a revised tool for assessing risk of bias in randomised trials. BMJ 366:14898. https://doi.org/10.1136/bmj.14898

20. Higgins JPT, Li T, Deeks JJe (2019) Chapter 6: Choosing effect measures and computing estimates of effect. In: Higgins JPT, Thomas J, Chandler J et al (eds) Cochrane handbook for systematic reviews of interventions version 6.0 (updated July 2019). Cochrane

21. Egger M, Davey Smith G, Schneider M, Minder C (1997) Bias in meta-analysis detected by a simple, graphical test. BMJ 315(7109):629-634. https://doi.org/10.1136/bmj.315.7109.629

22. Furlan AD, Malmivaara A, Chou R, Maher CG, Deyo RA, Schoene M, Bronfort G, van Tulder MW (2015) 2015 Updated method guideline for systematic reviews in the cochrane back and neck group. Spine (Phila Pa 1976) 40(21):1660-1673. https://doi. org/10.1097/brs.0000000000001061

23. Arden NK, Price C, Reading I, Stubbing J, Hazelgrove J, Dunne C, Michel M, Rogers P, Cooper C (2005) A multicentre randomized controlled trial of epidural corticosteroid injections for sciatica: the WEST study. Rheumatology (Oxford) 44(11):1399_ 1406. https://doi.org/10.1093/rheumatology/kei028

24. Bush K, Hillier S (1991) A controlled study of caudal epidural injections of triamcinolone plus procaine for the management of intractable sciatica. Spine (Phila Pa 1976) 16(5):572-575. https:// doi.org/10.1097/00007632-199105000-00015

25. Carette S, Leclaire R, Marcoux S, Morin F, Blaise GA, St-Pierre A, Truchon R, Parent F, Levésque J, Bergeron V, Montminy P, Blanchette C (1997) Epidural corticosteroid injections for sciatica due to herniated nucleus pulposus. N Engl J Med 336(23):16341640. https://doi.org/10.1056/nejm199706053362303

26. Cohen SP, White RL, Kurihara C, Larkin TM, Chang A, Griffith SR, Gilligan C, Larkin R, Morlando B, Pasquina PF, Yaksh TL, Nguyen C (2012) Epidural steroids, etanercept, or saline in subacute sciatica: a multicenter, randomized trial. Ann Intern Med 156(8):551-559. https://doi.org/10.7326/0003-4819-156-8-20120 4170-00002

27. Datta R, Upadhyay KK (2011) A randomized clinical trial of three different steroid agents for treatment of low backache through the caudal route. Med J Armed Forces India 67(1):25-33. https://doi. org/10.1016/s0377-1237(11)80007-9

28. Ghahreman A, Ferch R, Bogduk N (2010) The efficacy of transforaminal injection of steroids for the treatment of lumbar radicular pain. Pain Med 11(8):1149-1168. https://doi.org/10.1111/j.15264637.2010.00908.x

29. Ghai B, Kumar K, Bansal D, Dhatt SS, Kanukula R, Batra YK (2015) Effectiveness of parasagittal interlaminar epidural local anesthetic with or without steroid in chronic lumbosacral pain: a randomized. Double-Blind Clin Trial Pain Physician 18(3):237-248

30. Helliwell M, Robertson J, Ellis R (1985) Outpatient treatment of low-back pain and sciatica by a single extradural corticosteroid injection. Br J Clin Pract 39(6):228-231

31. Iversen T, Solberg TK, Romner B, Wilsgaard T, Twisk J, Anke A, Nygaard O, Hasvold T, Ingebrigtsen T (2011) Effect of caudal epidural steroid or saline injection in chronic lumbar radiculopathy: multicentre, blinded, randomised controlled trial. BMJ 343:d5278. https://doi.org/10.1136/bmj.d5278

32. Karppinen J, Malmivaara A, Kurunlahti M, Kyllönen E, Pienimäki T, Nieminen P, Ohinmaa A, Tervonen O, Vanharanta H (2001) Periradicular infiltration for sciatica: a randomized controlled 
trial. Spine (Phila Pa 1976) 26(9):1059-1067. https://doi.org/10. 1097/00007632-200105010-00015

33. Klenerman L, Greenwood R, Davenport HT, White DC, Peskett $S$ (1984) Lumbar epidural injections in the treatment of sciatica. Br J Rheumatol 23(1):35-38. https://doi.org/10.1093/rheumatolo gy/23.1.35

34. Manchikanti L, Singh V, Cash KA, Pampati V, Damron KS, Boswell MV (2012) Effect of fluoroscopically guided caudal epidural steroid or local anesthetic injections in the treatment of lumbar disc herniation and radiculitis: a randomized, controlled, double blind trial with a two-year follow-up. Pain Physician 15(4):273-286

35. Manchikanti L, Singh V, Cash KA, Pampati V, Falco FJ (2014) A randomized, double-blind, active-control trial of the effectiveness of lumbar interlaminar epidural injections in disc herniation. Pain Physician 17(1):E61-74

36. Manchikanti L, Cash KA, Pampati V, Falco FJ (2014) Transforaminal epidural injections in chronic lumbar disc herniation: a randomized, double-blind, active-control trial. Pain Physician 17(4):E489-501

37. Tafazal S, Ng L, Chaudhary N, Sell P (2009) Corticosteroids in peri-radicular infiltration for radicular pain: a randomised double blind controlled trial: one year results and subgroup analysis. Eur Spine J 18(8):1220-1225. https://doi.org/10.1007/ s00586-009-1000-2

38. Valat JP, Giraudeau B, Rozenberg S, Goupille P, Bourgeois P, Micheau-Beaugendre V, Soubrier M, Richard S, Thomas E (2003) Epidural corticosteroid injections for sciatica: a randomised, double blind, controlled clinical trial. Ann Rheum Dis 62(7):639-643. https://doi.org/10.1136/ard.62.7.639

39. Bicket MC, Gupta A, Brown CHt, Cohen SP, (2013) Epidural injections for spinal pain: a systematic review and meta-analysis evaluating the "control" injections in randomized controlled trials. Anesthesiology 119(4):907-931. https://doi.org/10.1097/ALN. 0b013e31829c2ddd

40. Cohen SP, Bicket MC, Jamison D, Wilkinson I, Rathmell JP (2013) Epidural steroids: a comprehensive, evidence-based review. Reg Anesth Pain Med 38(3):175-200. https://doi.org/10. 1097/AAP.0b013e31828ea086

41. Manchikanti L, Knezevic NN, Boswell MV, Kaye AD, Hirsch JA (2016) Epidural injections for lumbar radiculopathy and spinal stenosis: a comparative systematic review and meta-analysis. Pain Physician 19(3):E365-410

42. Manchikanti L, Nampiaparampil DE, Manchikanti KN, Falco FJ, Singh V, Benyamin RM, Kaye AD, Sehgal N, Soin A, Simopoulos TT, Bakshi S, Gharibo CG, Gilligan CJ, Hirsch JA (2015) Comparison of the efficacy of saline, local anesthetics, and steroids in epidural and facet joint injections for the management of spinal pain: a systematic review of randomized controlled trials. Surg Neurol Int 6(Suppl 4):S194-235. https://doi.org/10.4103/21527806.156598

43. Deeks JJ, Higgins JPT, Altman DGe, (2019) Chapter 10: Analysing data and undertaking meta-analyses. In: Higgins JPT, Thomas J, Chandler J et al (eds) Cochrane handbook for systematic reviews of interventions version 6.0 (updated July 2019). Cochrane

44. Gagnier JJ, Morgenstern H, Altman DG, Berlin J, Chang S, McCulloch P, Sun X, Moher D (2013) Consensus-based recommendations for investigating clinical heterogeneity in systematic reviews. BMC Med Res Methodol 13:106. https://doi.org/10. 1186/1471-2288-13-106

45. Ostelo RW, Deyo RA, Stratford P, Waddell G, Croft P, Von Korff M, Bouter LM, de Vet HC (2008) Interpreting change scores for pain and functional status in low back pain: towards international consensus regarding minimal important change. Spine (Phila Pa 1976) 33(1):90-94. https://doi.org/10.1097/BRS.0b013e3181 $5 \mathrm{e} 3 \mathrm{a} 10$
46. MacVicar J, King W, Landers MH, Bogduk N (2013) The effectiveness of lumbar transforaminal injection of steroids: a comprehensive review with systematic analysis of the published data. Pain Med 14(1):14-28. https://doi.org/10.1111/j.1526-4637.2012. 01508.x

47. Haefeli M, Elfering A (2006) Pain assessment. Eur Spine J. https:// doi.org/10.1007/s00586-005-1044-X

48. Mehling WE, Gopisetty V, Acree M, Pressman A, Carey T, Goldberg H, Hecht FM, Avins AL (2011) Acute low back pain and primary care: how to define recovery and chronification? Spine (Phila Pa 1976) 36(26):2316-2323. https://doi.org/10.1097/BRS. 0b013e31820c01a6

49. Moore A, McQuay H, Gavaghan D (1996) Deriving dichotomous outcome measures from continuous data in randomised controlled trials of analgesics. Pain 66(2-3):229-237. https://doi.org/10. 1016/0304-3959(96)03032-1

50. Vavken P, Ganal-Antonio AK, Quidde J, Shen FH, Chapman JR, Samartzis D (2015) Fundamentals of clinical outcomes assessment for spinal disorders: clinical outcome instruments and applications. Glob Spine J 5(4):329-338. https://doi.org/10.1055/s0034-1396046

51. Karppinen J, Ohinmaa A, Malmivaara A, Kurunlahti M, Kyllönen E, Pienimäki T, Nieminen P, Tervonen O, Vanharanta H (2001) Cost effectiveness of periradicular infiltration for sciatica: subgroup analysis of a randomized controlled trial. Spine (Phila Pa 1976) 26(23):2587-2595. https://doi.org/10.1097/00007632200112010-00013

52. Abdi S, Datta S, Lucas LF (2005) Role of epidural steroids in the management of chronic spinal pain: a systematic review of effectiveness and complications. Pain Physician 8(1):127-143

53. Anesthesiologie SP-ePGvdNVv (2016) Protocol Veilig gebruik van epidurale corticosteroïden infiltraties. https://www.anesthesio logie.nl/publicaties/protocol-veilig-gebruik-epidurale-corticoste roiden-infiltraties

54. Chou R, Atlas SJ, Stanos SP, Rosenquist RW (2009) Nonsurgical interventional therapies for low back pain: a review of the evidence for an American Pain Society clinical practice guideline. Spine (Phila Pa 1976) 34(10):1078-1093. https://doi.org/10.1097/ BRS.0b013e3181a103b1

55. El-Yahchouchi CA, Plastaras CT, Maus TP, Carr CM, McCormick ZL, Geske JR, Smuck M, Pingree MJ, Kennedy DJ (2016) Adverse event rates associated with transforaminal and interlaminar epidural steroid injections: a multi-institutional study. Pain Med 17(2):239-249. https://doi.org/10.1111/pme.12896

56. Manchikanti L, Malla Y, Wargo BW, Cash KA, Pampati V, Fellows B (2012) A prospective evaluation of complications of 10,000 fluoroscopically directed epidural injections. Pain Physician 15(2):131-140

57. McGrath JM, Schaefer MP, Malkamaki DM (2011) Incidence and characteristics of complications from epidural steroid injections. Pain Med 12(5):726-731. https://doi.org/10.1111/j.1526-4637. 2011.01077.x

58. Carr CM, Plastaras CT, Pingree MJ, Smuck M, Maus TP, Geske JR, El-Yahchouchi CA, McCormick ZL, Kennedy DJ (2016) Immediate adverse events in interventional pain procedures: a multi-institutional study. Pain Med 17(12):2155-2161. https:// doi.org/10.1093/pm/pnw051

59. Debray TPA, Moons KGM, Riley RD (2018) Detecting smallstudy effects and funnel plot asymmetry in meta-analysis of survival data: a comparison of new and existing tests. Res Synth Methods 9(1):41-50. https://doi.org/10.1002/jrsm.1266

60. Pearce W, Raman S (2014) The new randomised controlled trials (RCT) movement in public policy: challenges of epistemic governance. Policy Sci 47(4):387-402. https://doi.org/10.1007/ s11077-014-9208-3 
61. Rogers W, Hutchison K (2017) Evidence-Based Medicine in Theory and Practice: Epistemological and Normative Issues. In: Schramme T, Edwards S (eds) Handbook of the philosophy of medicine. Springer, Dordrecht

62. Victora CG, Habicht JP, Bryce J (2004) Evidence-based public health: moving beyond randomized trials. Am J Public Health 94(3):400-405. https://doi.org/10.2105/ajph.94.3.400
Publisher's Note Springer Nature remains neutral with regard to jurisdictional claims in published maps and institutional affiliations. 